\title{
Effect of Spatial Orientation and Motor Rhythm Trainings on Motor Speed and Skill Performance Level of Soccer Juniors.
}

\author{
Amr Ali Shady \\ Sport Training Department, Faculty of Sport Education, Mansoura University. Egypt. \\ Mohammad Abdelsattar Mahmoud \\ Sport Training Department, Faculty of Sport Education, Mansoura University. Egypt.
}

\begin{abstract}
Objectives: to recognize the effect of spatial orientation and motor rhythm trainings on motor speed and skill performance level for soccer juniors .

Design: The training program was 8 weeks long, 3 training units per week where the spatial orientation and motor rhythm trainings time lasts from 30-40 minutes of the training unit time .
\end{abstract}

Participants: 26 soccer juniors under 17-18 years old were equally and randomly divided into two groups experimental $(n=13)$ and control $(n=13)$ groups .

Main Outcome Measures: The anthropometric (height and weight), spatial orientation ability (turning to touch the color test), motor rhythm ability (motor rhythm ability test), motor speed (dribbling test \& dribbling and shooting test) and skill performance (shooting test, dribbling test and passing with the appropriate strength test)

Results: Statistically differences were found on spatial orientation, motor rhythm, motor speed and skill performance between control and experimental groups for the experimental group .

Conclusions: from the results of this research and according to the existence of statistically significance for the experimental group, the researchers recommended that coaches should give a great deal of importance to developing the coordinative abilities through making it an essential part of soccer juniors training program.

Key words: Spatial Orientation, Motor Rhythm, Motor Speed, Skill Performance Level.

\section{Introduction}

$\mathrm{T}$ he rhythm is one of the effective means to help in the processes of education and training being linked to motor sense and a mean to clarify and be aware of the movement. That was referred to by Gouda (1990) study, clarifying that while acquisition of a new motor performance its rhythm realization has a major role in its acquisition and mastery.
That was also emphasizes by Southard (1996) clarifying the importance of rhythm in skill performance, as well as Southard, et. al (1993) did referring to the rhythm great impact during the motor performance.

According to both Mainl \& Schnabel (2006) and Mainl \& Schnabel (2007), motor rhythm is one of coordinative conditions of performance, which had a great importance in all kinds of sports, not only in sports or 
disciplines, its performance is determined by musical companion, but also to learn motor skills, requiring a high level of this capability during motor learning process.

Auditory support makes it easy for learners to understand the chronology of muscular effort required for performance, which is considered more effective through increasing athlete ability on handling this information, by the possibility of receiving and performing the rhythm.

Smolensky (1996) indicates that the correct timing and rhythm sequence in performing the skill has a major role in motor performance accuracy and control, and helps the player to perform and sense each move.

Both Hirtz (1985) and Prätorius (2008) agreed on the motor rhythm application importance, comes first in skills acquisition and mastery in different activities and on its performance specifying nature in several sports. Hotz (2002) also pointed to its aesthetic, economical and harmonic importance during motor execution.

Both Meinel \& Schnabel (2006) mentioned that the first principle of motor rhythm relies primarily on auditory (often musical) or (eg: when giving an ideal model of movement) realization of the rhythm given in advance, which was implemented in motor handling. While the second principle refers to the fact that in many of the sport movements an external rhythm is associated with motor implementation given in advance, as well as an internal rhythm does (self regulatory rhythm).

This means that providing a model of performance is of great importance in the ideal implementation of the motor track in its appropriate dynamic chronological sequence. Here, the motor-sense information occupies a special importance in percepting performance model rhythm.

Neumaier (2009) added that there are two major factors we must distinguish between, in rhythmic ability:

- Perception which refer to receiving one of the external rhythms given in advance, for example through music, and implementing it in chronological rhythm pattern identified movements. As well as the dynamic design of time among pulses of rhythm with the movements.

- Creating a matching dynamic chronological order, which, contributes to reach a motor path featured by flow and motor beauty in sports, depending on motor track evaluation.

The player mastery degree of the rhythmic ability could be known by his ability to adapt to the motor rhythm of another player, and then the conscious breakthrough of the opponent player rhythm is founded in the team sports.

Kirchner \& Pöhlmann (2005) see the motor rhythm definition as "the player ability to recognize chronological and dynamic order of motor performance he does, to save this plentiful information as a rhythmic guideline simplified pattern, and then to use this pattern to guide motor dealings through the motor control (Settings) process ".

Here the strong correlation between each of the ability to perceive motor rhythm and the ability of spatial orientation appears. The ability of spatial orientation is the ability of meaningful and appropriate change of the body position and movement in time and space for a specific area of the playground or a moving target (the ball, opponent, and colleague). 
The basis here is built on the reception and processing of information, as well as the motor-sense information, here appears the integration between each of these two abilities in realizing the situation and the opponent's motor rhythm.

The ability to control and direct the movement and realize its arrangement chronologically and spatially, the change in the position and the movement of parts of the body as a whole in the space does not depend only on the spatial change of parts of the body, as the specified requirements of this capability, which have been developed for each sportive activity is on a enormous degree of difference.

In team sports, including soccer, player must realize his body position as well as position changes inside the available space for motor handling (playground area, whether large or small) with partial cognitive of many other moving targets (colleagues, opponents, ball), thus taking into account the change in the body position, depending on the ongoing changes in the game situation.

The relationship between the so-called Timing, which is the regular and accurate motor handle, performed in correct timing, as an expression for the optical motor accounts of the movement performances (eg meeting the ball at the highest point when you hit ball by head, as well as the appropriate time to start a wall pass (1-2) in soccer).

Neumaier (2009) clarified that each motor track - includes a transition move - requires the highest degree of realizing the precise location around the movement linked to body position and movement. These requirements increase with situations changes in the surrounding environment (the playing environment).
Prätorius (2008) and Hirtz (1985) emphasize that the great importance of the spatial orientation ability emanates primarily from the executive role of the optical information during motor handles, and thus it is a comprehensive basis for the development of compatibility.

The researchers believe that the play nature of soccer imposed on the players to keep on with the permanent changing game actions including the variables contained in the game situation (ball - colleagues - opponent - the player position towards the goal ....), which may negatively affect the motor speed and motor performance selection proper to the situation. This gives a great importance to the spatial orientation as one of the variables that may affect the selection and execution of the right skill performance and its proper speed.

Spatial rhythm has a great importance for team sports because of the specialty of its exercises and movements variety. As all the movements of motor rhythm require balance, body position is changed between flexion, extension and straightening...., it is also used in most types of team sports warming-up.

The researchers noticed, through their work as juniors sector coaches, Insufficiency in motor speed level of juniors through motor performances, as the slowness through performing trap movements with and without the ball, dribbling and changing direction, passing and receiving, which could be due to players inability on realizing self-motor rhythm for those skills and therefore inability to perceive time and dynamic sequence, which helps increasing the rate of speed at performance.

As the soccer juniors in late ages 17-18 generally may not be sufficiently subjected to coordinative abilities training, or especially to spatial orientation and rhythmic ability 
train during growth spurt of these abilities, the researchers believe that applying this research on that age stage will identify the rate of compensating losses in those two abilities level and its impact on the motor speed level and skill performance for soccer junior.

\section{Aim of Research}

This research aims to identifying "Effect of Spatial Orientation and Motor Rhythm Trainings on Motor Speed and Skill Performance Level of Soccer Juniors" Through:

- Effect of spatial orientation and motor rhythm trainings on motor speed level for soccer juniors.

- Effect of spatial orientation and motor rhythm trainings on skill performance level for soccer juniors.

- The rate of improvement in spatial orientation level - motor rhythm and motor speed - skill performance level for soccer juniors.

\section{Hypotheses}

- There are statistically significant differences in the variables under consideration between pre-test and posttest measurements of the experimental group for the post-test.

- There are statistically significant differences in the variables under consideration between pre-test and post- test measurements of the control group for the post-test.

- There are statistically significant differences in the variables under consideration between post-test measurements of experimental group and control group for the post-test measurement of the experimental group.

\section{Methods}

\section{Research Methodology}

The researchers used the experimental approach by using experimental design of two groups, experimental group and control group, owing to its suitability of this study.

The experimental group was subjected to spatial orientation and motor rhythm trainings while the control group was trained by a traditional training program that did not include any coordinative abilities trainings.

\section{Research Sample}

26 soccer juniors under (18) years registered at the Egyptian Soccer Federation season 2012/2013 were equally and randomly divided into two groups experimental $(n=13)$ and control $(n=13)$ groups.

\section{Research Sample Modesty and Equivalence}

Sample modesty and equivalence in main variables (age - height -weight - training age) and under consideration variables were emphasized as described in tables (1) \& (2). 
Table (1)

Research sample homogeneity in experimental and control groups pre-test measurements

$n=26$

\begin{tabular}{|c|c|c|c|c|c|c|}
\hline \multicolumn{2}{|c|}{ Variables } & $\begin{array}{c}\text { Measurin } \\
\text { g unit }\end{array}$ & Average & median & deviation & $\begin{array}{c}\text { Skewness } \\
\text { Coefficient }\end{array}$ \\
\hline \multicolumn{2}{|c|}{ Age } & Age & 17.83 & 17.9 & 0.41 & -0.52 \\
\hline \multicolumn{2}{|c|}{ Height } & Height & 167.6 & 167 & 2.56 & 0.70 \\
\hline \multicolumn{2}{|c|}{ Weight } & Weight & 65.64 & 65 & 2.87 & 0.67 \\
\hline \multicolumn{2}{|c|}{ Training Age } & Years & 6.35 & 6 & 0.88 & 1.20 \\
\hline \multicolumn{2}{|c|}{ Spatial Orientation Ability } & $\mathbf{S}$ & 1.39 & 1.3 & 0.12 & 2.54 \\
\hline \multicolumn{2}{|c|}{ Motor Rhythm Ability } & $\mathbf{S}$ & 1.98 & 1.55 & 0.48 & 2.66 \\
\hline \multirow[t]{2}{*}{ Motor Speed } & $\begin{array}{c}\text { dribbling \& } \\
\text { shooting } \\
\end{array}$ & $\mathbf{S}$ & 45.79 & 4.6 & 0.92 & -0.69 \\
\hline & Dribbling & $\mathbf{S}$ & 41.23 & 42 & 1.38 & -1.68 \\
\hline \multirow{3}{*}{$\begin{array}{c}\text { Skill } \\
\text { performance } \\
\text { level }\end{array}$} & Passing & Number & 2.92 & 3 & 0.81 & -0.29 \\
\hline & Shooting & Points & 5.16 & 5 & 1.40 & 0.34 \\
\hline & Dribbling & $\mathbf{S}$ & 28.03 & 29 & 1.42 & -2.05 \\
\hline
\end{tabular}

T-Test $(0.05)=2.064$

Table (1): clarifies that the skewness which indicates the modesty of the data coefficient values of the research sample in distributio sample tuning variables lies between \pm 3

Table (2)

Research sample equivalence in experimental and control groups pre-test measurements

$\mathrm{n}=\mathbf{2 6}$

\begin{tabular}{|c|c|c|c|c|c|c|c|}
\hline \multirow{2}{*}{\multicolumn{2}{|c|}{ Variables }} & \multirow{2}{*}{$\begin{array}{c}\text { Measuring } \\
\text { unit }\end{array}$} & \multicolumn{2}{|c|}{ Experimental Group } & \multicolumn{2}{|c|}{ Control Group } & \multirow{2}{*}{$\begin{array}{c}\text { T- } \\
\text { Test }\end{array}$} \\
\hline & & & Average & Deviation & Average & Deviation & \\
\hline \multicolumn{2}{|c|}{ Spatial Orientation Ability } & $\mathbf{S}$ & 1.37 & 0.11 & 1.45 & 0.12 & 1.55 \\
\hline \multicolumn{2}{|c|}{ Motor Rhythm Ability } & $\mathbf{S}$ & 1.89 & 0.38 & 2.11 & 0.56 & 1.16 \\
\hline \multirow{2}{*}{ Motor Speed } & $\begin{array}{c}\text { dribbling } \\
\text { \& shooting }\end{array}$ & $\mathbf{S}$ & 45.78 & 0.99 & 45.95 & 1.01 & 0.44 \\
\hline & dribbling & $\mathbf{S}$ & 40.48 & 1.63 & 40.71 & 1.02 & 0.44 \\
\hline \multirow{3}{*}{$\begin{array}{c}\text { Skill } \\
\text { performance } \\
\text { level }\end{array}$} & passing & Number & 3 & 0.91 & 2.92 & 0.76 & 0.23 \\
\hline & shooting & Points & 5.15 & 1.34 & 5 & 1.58 & 0.27 \\
\hline & dribbling & $\mathbf{S}$ & 27.17 & 1.32 & 28.46 & 1.56 & 1.33 \\
\hline
\end{tabular}

T-Test $(0.05)=2.064$

Table (2): clarifies that there are no statistically significant differences in the under consideration variables between the pre-tests of the experimental group and control group as all the T-Test values are less than their tabulated value at (0.05) significance level which indicates the sample equivalence . 


\section{Research Variables}

The research variables were measured through the following tests:

- Spatial orientation ability (turning to touch the color test) referred to at Abdelsattar (2012).

- Motor rhythm ability test referred to at Drobe (1999).

- Motor speed (dribbling test- dribbling and shooting test) referred to at Weinek (2004).

- Skill performance level (passing using appropriate strength test) referred to at Drobe (1999), (shooting accuracy test) referred to at Baatjes (2006) and (dribbling test) referred to at Southard and Mircale (1993).

\section{Exploratory Study}

The exploratory study was performed on a sample of 10 juniors out of the original sample. It aims to indicating the scientific factors of spatial orientation and motor rhythm abilities, motor speed and skill performance under consideration.

\section{Study Procedures}

The researchers calculated the scientific factors (Validity - Reliability) for the tests applied in this study using validity differentiation test and re-test applying for calculating reliability as shown in tables (3) and (4).

Table (3)

Validity factor for the applied tests in study

$n 1+n 2=20$

\begin{tabular}{|c|c|c|c|c|c|c|c|}
\hline \multirow{2}{*}{\multicolumn{2}{|c|}{ Variables }} & \multirow{2}{*}{$\begin{array}{c}\text { Measuring } \\
\text { unit }\end{array}$} & \multicolumn{2}{|c|}{ Featured Group } & \multicolumn{2}{|c|}{ Non-Featured Group } & \multirow{2}{*}{ T- Test } \\
\hline & & & Average & Deviation & Average & Deviation & \\
\hline \multicolumn{2}{|c|}{ Spatial Orientation Ability } & $\mathbf{S}$ & 1.2 & 0.083 & 1.45 & 0.124 & $* 5.361$ \\
\hline \multicolumn{2}{|c|}{ Motor Rhythm Ability } & $\mathbf{S}$ & 1.52 & 0.414 & 2.04 & 0.62 & $* 2.199$ \\
\hline \multirow{2}{*}{ Motor Speed } & $\begin{array}{l}\text { dribbling } \\
\text { \& shooting }\end{array}$ & $\mathbf{S}$ & 42.25 & 0.824 & 45.84 & 1.09 & $* 8.309$ \\
\hline & dribbling & $\mathbf{S}$ & 37.61 & 1.14 & 42.68 & 1.16 & $* 9.864$ \\
\hline \multirow{3}{*}{$\begin{array}{c}\text { Skill } \\
\text { performance } \\
\text { level }\end{array}$} & passing & Number & 4.5 & 0.707 & 2.80 & 0.632 & *5.667 \\
\hline & shooting & Points & 7.70 & 0.823 & 5.0 & 1.56 & $* 4.832$ \\
\hline & dribbling & $\mathbf{S}$ & 24.66 & 0.837 & 27.65 & 1.58 & $* 5.276$ \\
\hline
\end{tabular}

T-Test $(0.05)=2.101$

Table (3): indicates the existence of of the study at (0.05) significance level significant differences between the featured indicating the validity of applied tests. and non-featured groups in the applied tests 
Table (4)

Reliability factor for the applied tests in study

$\mathrm{n} 1=\mathbf{1 0}$

\begin{tabular}{|c|c|c|c|c|c|c|c|}
\hline \multirow{2}{*}{\multicolumn{2}{|c|}{ Variables }} & \multirow{2}{*}{$\begin{array}{c}\text { Measuring } \\
\text { unit }\end{array}$} & \multicolumn{2}{|c|}{ First Application } & \multicolumn{2}{|c|}{ Second Application } & \multirow{2}{*}{$\begin{array}{l}0 \\
0\end{array}$} \\
\hline & & & Average & Deviation & Average & Deviation & \\
\hline \multicolumn{2}{|c|}{ Spatial Orientation Ability } & $\mathbf{S}$ & 1.5 & 0.12 & 1.44 & 0.1 & 0.92 \\
\hline \multicolumn{2}{|c|}{ Motor Rhythm Ability } & $\mathbf{S}$ & 2.36 & 0.42 & 2.09 & 0.31 & 0.97 \\
\hline \multirow[t]{2}{*}{ Motor Speed } & $\begin{array}{c}\text { dribbling \& } \\
\text { shooting }\end{array}$ & $\mathbf{S}$ & 46.18 & 0.72 & 46.34 & 0.72 & 0.96 \\
\hline & Dribbling & $\mathbf{S}$ & 43.11 & 0.74 & 39.68 & 0.90 & 0.97 \\
\hline \multirow{3}{*}{$\begin{array}{c}\text { Skill } \\
\text { performance } \\
\text { level }\end{array}$} & Passing & Number & 3.1 & 0.57 & 3.8 & 0.63 & 0.68 \\
\hline & Shooting & Points & 5.2 & 1.39 & 6.7 & 1.06 & 0.87 \\
\hline & Dribbling & $\mathbf{S}$ & 28.26 & 1.17 & 27.36 & 0.88 & 0.96 \\
\hline
\end{tabular}

Correlation coefficient $(0.05)=0.602$

Table (4): indicates the existence of covariant correlation at (0.05) significance level between the first and the second applications of the tests on the exploratory study sample. The correlation coefficients values confined to $0.68: 0.97$ indicating the reliability of applied tests.

\section{The Training Program Applied Procedures}

The researchers specified some points through which the training program could be developed:

- The training program period is 8 -weeks.

- Training units per week are (3) units.

- The training unit period ranges from 100 to 130 minutes.

- Spatial orientation and motor rhythm trainings period through the training unit ranges between (30-45) minutes.

- The used spatial orientation and motor rhythm trainings load intensity (less than the maximum intensity - maximum intensity).

- The used training method - interval high intensity.

- Spatial orientation and motor rhythm trainings to be immediately placed after the warming-up.

- The performance time should not exceed 20-30 seconds.

- The repetitions number $(6-8)$.

- The groups number (3-4) groups.

- The between groups rest period (2 - 3) minutes.

In juniors training, it is important to strengthen the coordinative elements individually through training, while for the higher level players, it is important during training to apply complex methods, under time, spatial, and opponent pressure. 


\section{Results}

Table (5)

Difference between pre-test and post-test variables averages in experimental group

$\mathbf{n}=\mathbf{1 3}$

\begin{tabular}{|c|c|c|c|c|c|c|c|c|}
\hline \multirow{2}{*}{\multicolumn{2}{|c|}{ Variables }} & \multirow{2}{*}{ 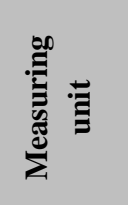 } & \multicolumn{2}{|c|}{ Pre-test } & \multicolumn{2}{|c|}{ Post-test } & \multirow{2}{*}{ T-test } & \multirow{2}{*}{ 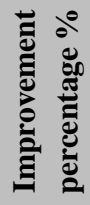 } \\
\hline & & & Average & Deviation & Average & Deviation & & \\
\hline \multicolumn{2}{|c|}{ Spatial Orientation Ability } & $\mathbf{S}$ & 1.37 & 0.11 & 1.24 & 0.09 & $* 7.22$ & 9.85 \\
\hline \multicolumn{2}{|c|}{ Motor Rhythm Ability } & $\mathbf{S}$ & 1.89 & 0.38 & 1.50 & 0.38 & *6.12 & 20.42 \\
\hline \multirow{2}{*}{ Motor Speed } & $\begin{array}{c}\text { dribbling \& } \\
\text { shooting }\end{array}$ & $\mathbf{S}$ & 45.78 & 0.99 & 42.33 & 0.88 & $* 28.59$ & 7.54 \\
\hline & Dribbling & $\mathbf{S}$ & 40.48 & 1.63 & 37.63 & 1.02 & *11.82 & 7.04 \\
\hline \multirow{3}{*}{$\begin{array}{c}\text { Skill } \\
\text { performance } \\
\text { level }\end{array}$} & Passing & Number & 3 & 0.91 & 4.54 & 0.66 & $* 5.28$ & 51.28 \\
\hline & Shooting & Points & 5.15 & 1.34 & 7.54 & 1.13 & *6.82 & 46.27 \\
\hline & Dribbling & $\mathbf{S}$ & 27.70 & 1.32 & 24.99 & 1.03 & $* 18.62$ & 9.82 \\
\hline
\end{tabular}

T-Test $(0.05)=2.179$

Table (5): indicates the existence of and post-test of the experimental group for significant differences between the pre-test the post test.

Table (6)

Difference between pre-test and post-test variables averages in control group. $\quad n=13$

\begin{tabular}{|c|c|c|c|c|c|c|c|c|}
\hline \multirow{2}{*}{\multicolumn{2}{|c|}{ Variables }} & \multirow{2}{*}{ 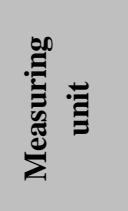 } & \multicolumn{2}{|c|}{ Pre-test } & \multicolumn{2}{|c|}{ Post-test } & \multirow{2}{*}{ T-test } & \multirow{2}{*}{ 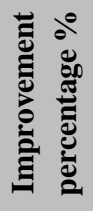 } \\
\hline & & & Average & Deviation & Average & Deviation & & \\
\hline \multicolumn{2}{|c|}{ Spatial Orientation Ability } & $\mathbf{S}$ & 1.45 & 0.12 & 1.41 & 0.09 & $* 3.57$ & 2.77 \\
\hline \multicolumn{2}{|c|}{ Motor Rhythm Ability } & $\mathbf{S}$ & 2.11 & 0.56 & 1.91 & 0.45 & $* 3.61$ & 9.35 \\
\hline \multirow[t]{2}{*}{ Motor Speed } & $\begin{array}{c}\text { dribbling \& } \\
\text { shooting } \\
\end{array}$ & $\mathbf{S}$ & 45.95 & 1.01 & 44.08 & 1.03 & $* 10.51$ & 4.07 \\
\hline & Dribbling & $\mathbf{S}$ & 40.71 & 1.02 & 39.33 & 1.03 & $* 8.36$ & 3.39 \\
\hline \multirow{3}{*}{$\begin{array}{c}\text { Skill } \\
\text { performance } \\
\text { level }\end{array}$} & Passing & Number & 2.92 & 0.76 & 3.62 & 0.65 & $* 5.20$ & 23.68 \\
\hline & Shooting & Points & 5 & 1.58 & 6.23 & 1.30 & $* 4.79$ & 24.62 \\
\hline & Dribbling & $\mathbf{S}$ & 28.46 & 1.56 & 26.88 & 1.22 & $* 11.50$ & 5.54 \\
\hline
\end{tabular}

T-Test $(0.05)=2.179$

Table (6) indicates the existence of under consideration variables for the postsignificant differences between the pre-test test. and post-test of the control group in the 
Figure 1

Under consideration variables improvement percentage

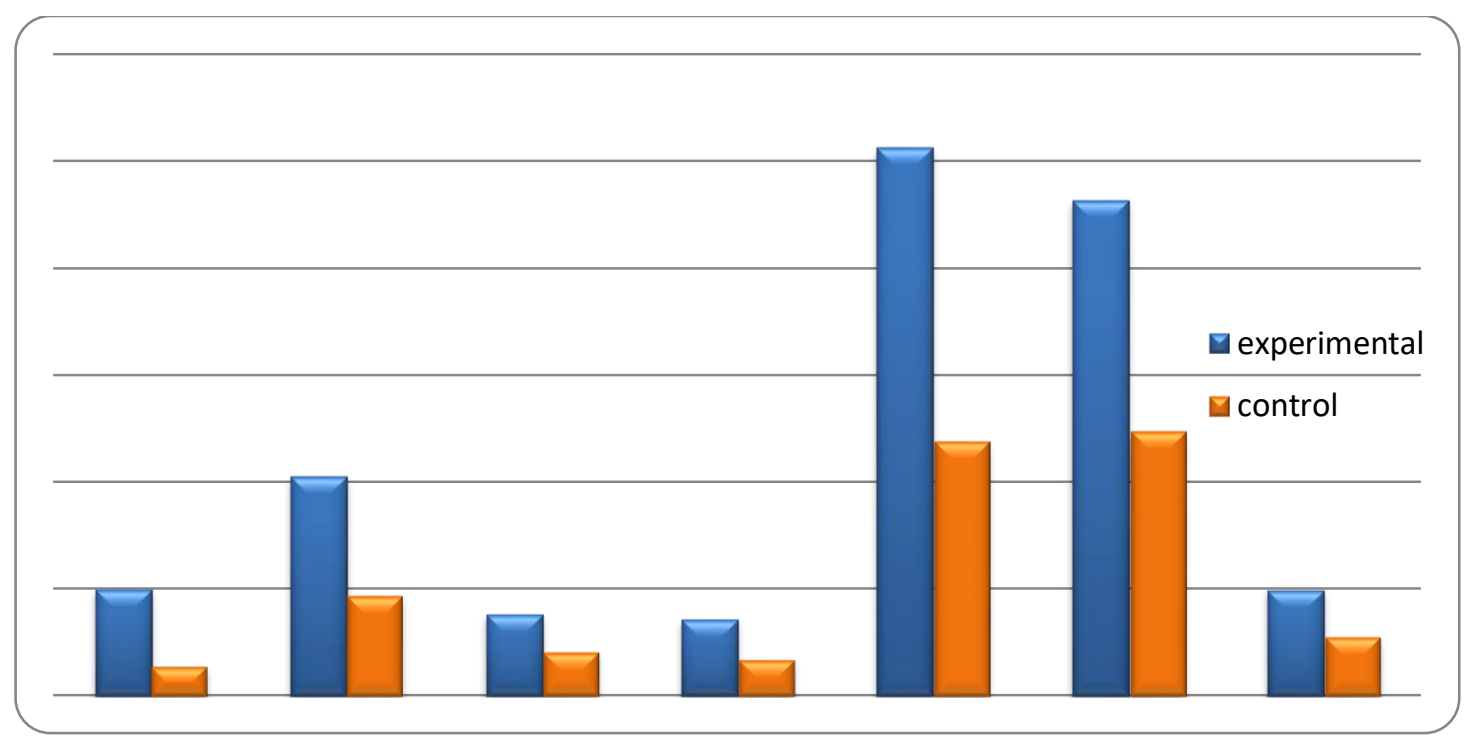

Figure 1: illustrates the improvement experimental groups in the under percentage between the control and consideration variables.

Table (7)

Difference between experimental group and control group post-test measurements averages $\quad n=26$

\begin{tabular}{|c|c|c|c|c|c|c|c|}
\hline \multirow{2}{*}{\multicolumn{2}{|c|}{ Variables }} & \multirow{2}{*}{$\begin{array}{c}\text { Measuring } \\
\text { unit }\end{array}$} & \multicolumn{2}{|c|}{ Experimental Group } & \multicolumn{2}{|c|}{ Control Group } & \multirow{2}{*}{ T- Test } \\
\hline & & & Average & Deviation & Average & Deviation & \\
\hline \multicolumn{2}{|c|}{ Spatial Orientation Ability } & $\mathbf{S}$ & 1.24 & 0.09 & 1.41 & 0.09 & $* 4.69$ \\
\hline \multicolumn{2}{|c|}{ Motor Rhythm Ability } & $\mathbf{S}$ & 1.50 & 0.38 & 1.91 & 0.45 & $* 2.487$ \\
\hline \multirow{2}{*}{ Motor Speed } & $\begin{array}{c}\text { dribbling \& } \\
\text { shooting }\end{array}$ & $\mathbf{S}$ & 42.33 & 0.88 & 44.08 & 1.03 & $* 4.678$ \\
\hline & dribbling & $\mathbf{S}$ & 37.63 & 1.02 & 39.33 & 1.03 & $* 4.244$ \\
\hline \multirow{3}{*}{$\begin{array}{c}\text { Skill } \\
\text { performance } \\
\text { level }\end{array}$} & passing & Number & 4.54 & 0.66 & 3.62 & 0.65 & $* 3.591$ \\
\hline & shooting & Points & 7.54 & 1.13 & 6.23 & 1.30 & $* 2.740$ \\
\hline & dribbling & $\mathbf{S}$ & 24.99 & 1.03 & 26.88 & 1.22 & $* 4.290$ \\
\hline
\end{tabular}

T-Test $(0.05)=2.064$

Table (7): indicates the existence of significant differences between the

\section{Discussion}

It is clear from Table (5) and figure (1) the existence of significant differences between the pre-test and post-test measurements of the experimental group in the spatial orientation ability, motor rhythm ability and motor speed variables (dribbling and experimental group and control group in the post-test measurements for the post-test.

shooting - dribbling) also the skill performance level (passing- shootingdribbling) for the post-test measurement with obvious significant degree as the calculated T-Test value confined between $(5.28,28.59)$, while the tabulated $\mathrm{T}$-Test value at $(0.05)$ level is (2.179). Also the improvement 
percentage confined between (7.04\%, $51.28 \%$ ), where the highest improvement percentage was in (passing as a skill variable) test, while the lowest improvement percentage was in (dribbling as a motor speed variable) test.

The obvious improvement in motor speed level, either in dribbling and shooting or only in dribbling is due to spatial orientation and motor rhythm abilities trainings that improved the ability of performing motor repetitions with high degree of speed, which may be referenced to the dynamic and chronological sequence, which helps to increase the rate of speed during performance and thus the optimal use of the needed energy.

These results agree with the results of Zak \& Duda (2003), Witkowski, et. al (2006), Taha (2007) and Mounir (2010) on the soccer players performance level in terms of skill and tactics depend on the coordinative skills level.

It is clear from Table (6) and the existence of significant differences between the pre-test and post-test of the experimental group in the spatial orientation and motor rhythm abilities and Motor speed (dribbling \& shooting dribbling) and the skill performance level ( passing -shooting - dribbling) for the posttest measurement with clear significant degree where calculated $\mathrm{T}$-Test value confined between $(2.77,24.62)$, while the tabulated T-Test value at (0.05) level is (2.179). As well as the improvement percentage confined between $(2.77,24.62)$, where the highest percentage of improvement in (shooting as a skill variable) test, while the lowest percentage of improvement (spatial orientation ability) test.

Table (7) initiated the existence of significant differences in the post-test between the experimental and control groups for the posttest of the experimental group in the variables under consideration (spatial orientation ability, Motor rhythm ability, Motor speed, skill performance level) where calculated is confined between (2.487, 23.74), while the tabulated T-Test value at (0.05) level is(2.179).

As the calculated T-Test value for the spatial orientation ability is 23.74 representing the highest value while the calculated T-Test value for the Motor rhythm ability is 2.487 representing the least value.

The researchers referenced their findings for these measurements to the training program, where spatial orientation and motor rhythm abilities applied to the experimental group leads to the acquisition of new motor models for the motor handlings as well as the diversity and control in motor handlings performance gained before, and to the use of the special coordinative training methods and techniques. These results agree with Witkowski, et. al (2006) Cicirko \&Buraczeeski (2007) and Liakh \& Witkowski (2010) results.

\section{Conclusions}

Through the study results the researchers found that the trainings of the spatial orientation and motor rhythm abilities have improved the motor speed level and further more improved the skill performance level of soccer juniors. From here we can emphasize that coaches should give a great interest to coordinative abilities development as well as the coordinative abilities should be an essential part of the training program for soccer juniors to raise a generation of talented soccer professional. Finally the researchers recommend the necessity of performing further similar studies on 
different samples in terms of age, sex and physical activity.

\section{References}

1. Abdelsattar M. "Determining Standardized Levels for Some Specific Coordination abilities for Soccer Juniors". PH.D, Faculty of Physical Education, Mansoura University, 2012.

2. Baatjes S.G. "Changes in the Anthropometric, Physical And Motor Characteristics Of Elite Soccer Players Aged 15 To 18 Years Within A Training Year", Master theses, Faculty of Health Sciences at the Nelson Mandela Metropolitan University, 2006.

3. Cicirko L.\& Buraczeeski T. "Diagnosing Motor Coordination Abilities In Training Juniors In Football", Young Sports Science Of Ukraine, Actual Problems Of Athletes. T. III. S.334-337,2007.

4. Drobe M. "Zur Talentförderung im Deutschen Fußballbund"- eine empirische Untersuchung unter Berücksichtigung von Ausprägung und Trainierbarkeit koordinativer Fähigkeiten, 1. Auflag, GrinVerlag, Dortmund,70-79,1999.

5. Hirtz P.'Koordinative Fähigkeiten Im Schulsport", Volkseigener Verlag, Berlin,35, 1985.

6. Hotz A. Dank Koordinatiever Kompetenz Mehr Leistungseffeizienz! In G.Ludwig \& B.Ludwig (Hrsg.). Koordinative Faehigkeiten-Koordinative-Kompetenz, Psychomotorik In Forschung Und Praxis,35, S. 84-90, 2002.

7. Gouda M. Effect Of A Proposed Program Using The Motor Rhythm On The Skill Level For Overwhelming Strike , Bulwark And Some Special Physical Characteristics. Sport Sciences And Arts, Faculty Of Physical Education For Girls, Helwan University. Vol 2(1), Pp. 246-325, 1990.

8. Kirchner G.\& Puehlmann R. Lehrbuch Der Sportmotorik, Universitaet Kassel, Zimmermann+Kaul Gbr, Kassel, 115,2005.

9. Liakh V.\& Witkowski Z. Development And Training Of Coordination Skills In 11- To 19- Year- Old Soccer Players, ISSN 03621197, Human Phzsiologz, Vol. 36, No. I, Pp. 64-71, 2010.

10. Meinel K. \& Schnabel G. Bewegungslehr Sportmotorik, 10 Durchgesehene Verlag, Südwest Verlag, München, 216-218, 2006.
11. Meinel K. \& Schnabel G. Bewegungslehr Sportmotorik, 11 Durchgesehene Verlag, Südwest Verlag,München,225-227, 2007.

12. Mounir H. The Effect Of A Training Program To Develop The Ability To React Effectively Perform On Some Offensive Skills Of The Individual Arising Football. Faculty Of Physical Education, Mansoura University , 2010.

13. Neumaier A. Koordinative Anforderungsprofil

Undkoordinationstraining, sportverlag Strauß, ,4. Überarbeitete Auflage, Köln, 121-122, 2009.

14. Prätorius B. Entwicklung Eines Koordinations Tests Für Kinder Im Grundschulalter Und Dessen Validierung Mit Hilfe Biomechnischer Methoden, Cuviller Verlag, Göttingen, 102,2008.

15. Smolensky V.M. Gymenastics For Physical Education Majors, Physical Education And Culture, Muscow,1996.

16. Southrad D. \& Amos B. Rhythmicity And Preperformance Ritual: Stabilizing Aflexible Systeme, Research Quarterly For Exercise And Sport, 67(3), 288-296,1996.

17. Southard D. \& Mircale A. "Rhythmicity Vritual, And Motor Performance: A Study Of Free Throw Shooting In Rashetball" Research Quarterly For Exercise And Sport, Vol. 64(3), 284-290, 1993.

18. Taha S. The Effect Of A Training Program For Some Coordinative Abilities On The Efficiency Of Head Ball Strike Performance For Soccer Juniors. Master Thesis, Faculty Of Physical Education, Mansoura University, 2007.

19. Weinek J. Optimales Fussballtraining, 4., ueberarbeitete Auflage, Das Konditionstraining des Fussballspielers, Spitta Verlag GmbH \& Co. KG,467468,2004.

20. Witkowski Z. Gargula L. \& Ljach W. Factor Structure Of Technical And Coordination Potential Of Soccer Players Aged 15-18, Journal Of Human Kinetics Volume 15, 83-96, 2006.

21.Zak S. \& Duda H. Level Of Coordinating Ability But Efficiency Of Game Of Young Football Players, Www.Awf.Krakow.Pl/Jedn/Gryzesps.Pdf. 
